\title{
Intrusion of Dacron suture knot 15 years after scleral buckling
}

Ruiping Gu' ${ }^{1}$ Xiujuan Chen ${ }^{2}$, Fang Song ${ }^{1}$, Chunhui Jiang ${ }^{1 *}$, Haohao Zhu ${ }^{3^{*}}$ and Gezhi Xu ${ }^{1,4,5}$

\begin{abstract}
Background: We present a case of intrusion of a suture knot 15 years after scleral buckling surgery.

Case presentation: A 62-year-old woman with high myopia had undergone scleral buckling surgery in her left eye 15 years previously for rhegmatogenous retinal detachment. She recently displayed highly elevated intraocular pressure, with hyphema and vitreous hemorrhage. After the blood was cleared, a ring-shaped protrusion was noted around the equator of the eyeball, with a blue suture knot standing out on its surface and extending into the vitreous cavity at 5 o'clock. The suture knot was removed successfully. Mass spectrometry revealed that the material of the suture was polyethylene terephthalate, or Dacron. One week later, at the place where the suture knot had been located, the choroidal and retinal tissue disappeared and the silicone buckle remained an uncovered intrusion, whereas the rest of the retina was still attached.
\end{abstract}

Conclusions: The suture knot was possibly the one used to close the drainage port for subretinal fluid, which was covered by the encircling band. During the buckling procedure, covering a nonabsorbable suture, which is usually placed where the sclera is compromised by trauma or the surgical incision, with an encircling band may lead to the intrusion of the suture. Therefore, a soft absorbable suture may be preferable, if possible.

Keywords: Scleral erosion, Dacron, Scleral buckling surgery, Secondary glaucoma

\section{Background}

'Intrusion' is the erosion and protrusion of a scleral suture or implant into the vitreous cavity [1]. Pathological myopia, glaucoma, and scleral buckle tension are strong risk factors for intrusion [2]. Silicone rubber, silicone buckles, silicone sponge, the Arruga suture, and polyethylene tubes have been reported to induce ocular intrusion [1,3]. Many cases of encircling suture intrusion have been reported in the literature $[4,5]$. However, there have been relatively few reports of the intrusion of the suture knot or anchoring suture [6, 7]. Here, we report a case of the intrusion of a Dacron suture knot 15 years after scleral buckling surgery.

\section{Case presentation}

A 62-year-old woman had undergone vitrectomy 30 years previously for traumatic vitreous hemorrhage,

\footnotetext{
*Correspondence: chhjiang70@163.com; haohao700315@163.com

1 Department of Ophthalmology and Vision Science, Eye and ENT Hospital of

Fudan University, 83 Fenyang Rd, Shanghai 200031, People's Republic of China

${ }^{3}$ Department of Ophthalmology, People's Hospital of Shanghai, No. 5,

Shanghai 200240, People's Republic of China

Full list of author information is available at the end of the article
}

scleral buckling surgery 15 years previously for rhegmatogenous retinal detachment, and phacoemulsification without intraocular lens implantation 1 year previously for cataract in her left eye. She suffered acute loss of vision in her left eye 4 months before admission to our hospital, with pain, left-sided headache, and nausea, and consulted another hospital. Records show that the visual acuity in her left eye was light perception and the intraocular pressure (IOP) was $50 \mathrm{mmHg}$, and a slit-lamp examination showed diffuse corneal edema associated with hyphema and vitreous hemorrhage. IOP was $25 \mathrm{mmHg}$ after the administration of glaucoma medications $\left(\mathrm{Azopt}^{\circ}\right.$ Eye Drops containing brinzolamide; Timolol Eye Drops containing timolol maleate; Alphagan $^{\circ}$ containing brimonidine tartrate), accompanied by the relief of both headache and nausea. The patient had experienced a relapse, with pain, left-sided headache, and nausea, 4 days before attending our hospital. Upon examination, her left eye showed visual acuity of light perception, diffuse corneal edema, hyphema, and vitreous hemorrhage (Fig. 1a), and an IOP of $45 \mathrm{mmHg}$. B-ultrasound showed vitreous opacities, and a 

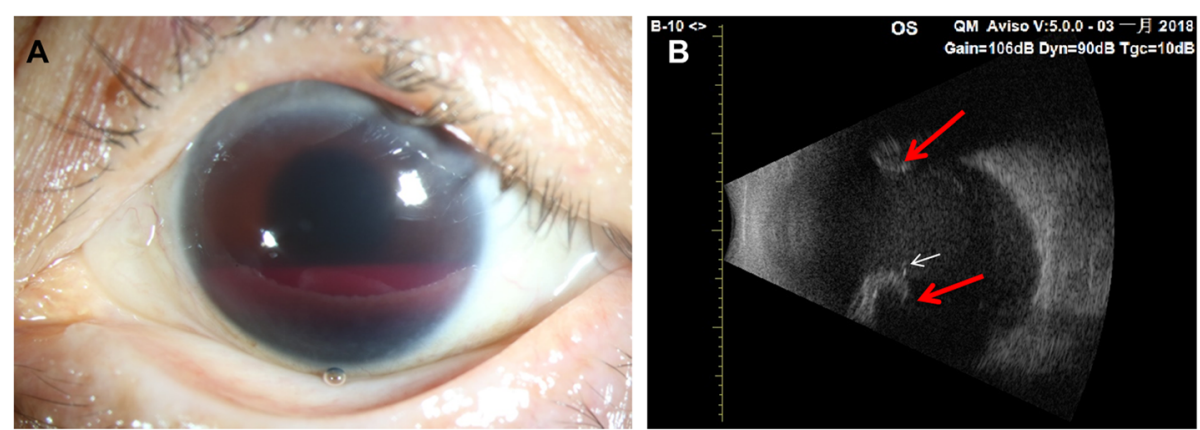

Fig. 1 A Anterior segment photograph of the left eye showing diffuse corneal edema and hyphema. B: B-mode ultrasound scan of the patient's left eye. High-luminance image of the scleral buckle protrusion showing acoustic shadow. Red arrow: protrusion of the scleral buckle; white arrow: acoustic shadow that may represent erosion of the suture node

high-luminance indentation of the eye wall with an acoustic shadow could be seen in the vitreous cavity on the B-scan (Fig. 1b). The axial length was $33.70 \mathrm{~mm}$ (IOLMaster 500, Zeiss). The patient was diagnosed with secondary glaucoma and treated with lavaging of the anterior chamber and vitreous cavity.

After the vitreous haemorrhage was cleared, a blue suture knot was detected standing out on retinal surface and projecting into the vitreous cavity at 5 o'clock (Fig. 2a). Using forceps, we found that the knot was loosely connected to the underlying tissue, and we removed it with forceps like any other intraocular foreign body, causing no haemorrhage or other complications (Fig. 2b). The next day, the visual acuity in the patient's left eye was hand motion, the IOP was $14.9 \mathrm{mmHg}$, and her pain was relieved. One week later, her best correct visual acuity was hand motion and her IOP was 13.6 $\mathrm{mmHg}$ in the left eye without anti-glaucoma medication. The vitreous was clear, the retina was still attached, and the ring-shaped protrusion was still visible around the equator. Around 5 o'clock, where the suture knot had been located, the choroid and retinal tissue were missing and the silicone buckle had penetrated into the vitreous cavity (Fig.3). We opted to treat the patient with steroid eye drops and conservative follow-up (observation), unless retinal redetachment or vitreous haemorrhage occurred.

Microscopy showed the suture as a multifilament of four fibers, each having 11 microfibers of diameter $16 \mu \mathrm{m}$ (Fig. 4). Mass spectrometry revealed that the material was polyethylene terephthalate (PET) (Fig. 5), possibly Dacron.

\section{Discussion}

Most reports of suture intrusion have concerned encircling sutures $[4,5]$, which are actually encircling bands. The intrusion of an anchoring suture or suture knot is relatively rare $[6,7]$. Here, we have reported a case of the intrusion of a PET suture knot 15 years after scleral buckling surgery.
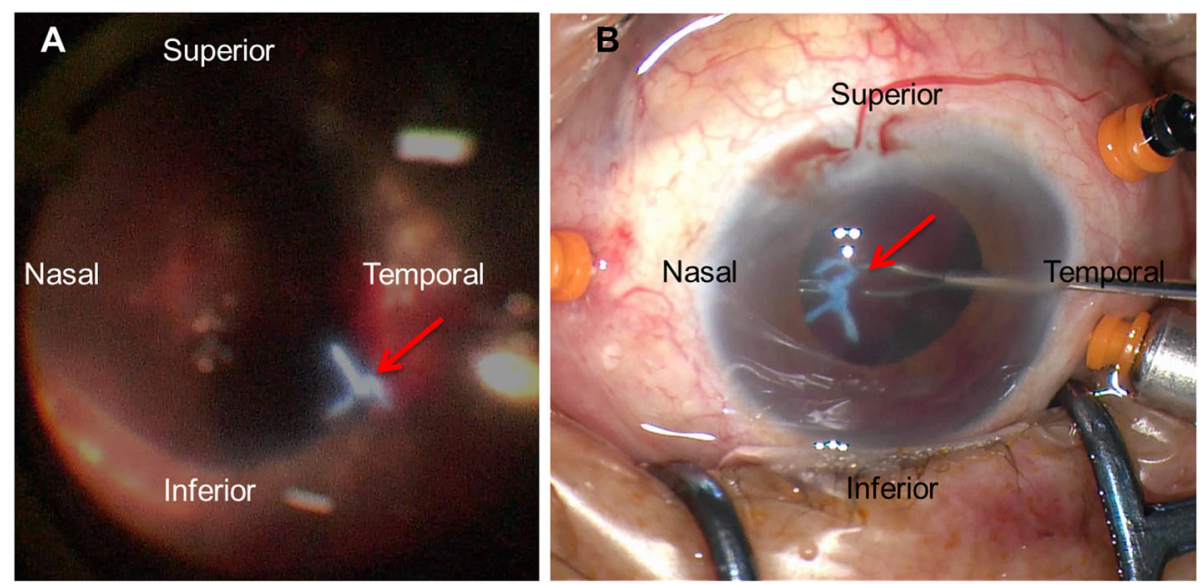

Fig. 2 Intraoperative images showing intrusion of the scleral suture node in the left eye. Red arrow: suture node 


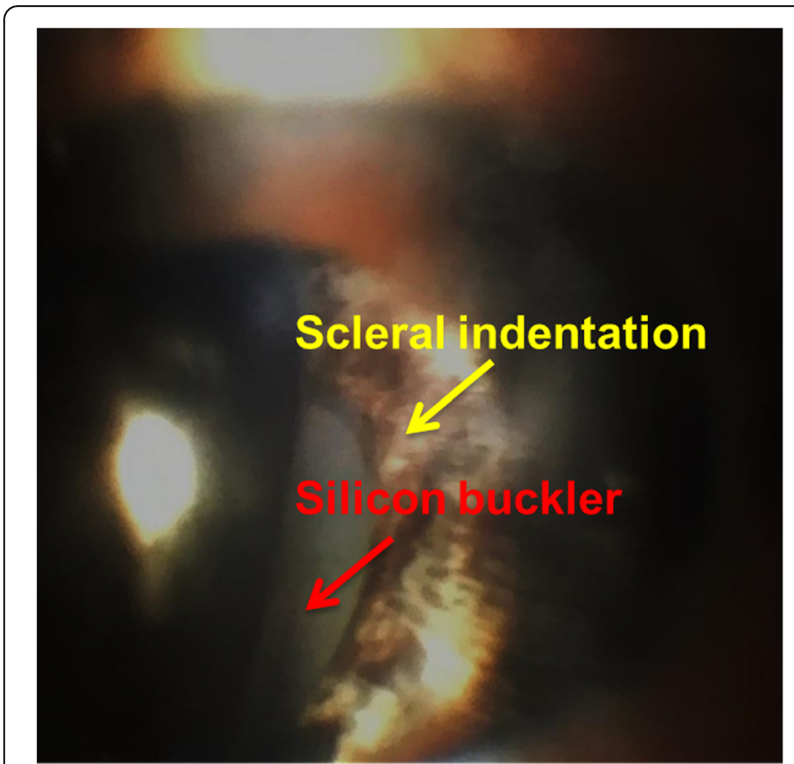

Fig. 3 Fundus photograph of the left eye during a slit-lamp examination showing the penetration of the silicon buckle on the inferior temporal segment 1 week after vitrectomy in the left eye. Red arrow: protrusion of the silicon buckle; yellow arrow: scleral indentation

The manifestations of intrusion vary, from asymptomatic to severe visual loss attributable to vitreous haemorrhage or retinal detachment [1, 2, 8-11]. In our case, the patient presented with highly elevated IOP and eye pain, headache, and nausea, and a clinical examination detected hyphema and vitreous haemorrhage. The intrusion of the suture knot was only found during surgery, so in patients with a history of scleral buckling, the possibility of intrusion must be considered.

An analysis showed that the suture was PET, possibly Dacron, a nonabsorbable suture from Alcon. PET is a compound synthesized from ethylene glycol and terephthalic acid in a polycondensation reaction, and is highly resistant to disintegration when buried in tissue $[12,13]$. In our patient, the suture knot was resting on a ring-shaped protrusion, and both the knot and the encircling silicone band were intact. Therefore, it is unlikely that the node was the anchoring suture for the encircling silicone band, but rather that the suture had been used to close the drainage port for subretinal fluid, and was covered by the encircling band. Weinberger reported that the intrusion of anchoring sutures occurs as a late complication of retinal detachment surgery when the extra-scleral buckling technique is used [7]. But in our case, the suture was not the anchoring one. Schepens reported that erosion commences and progresses as the implant is held firmly against the sclera by the sutures, the encircling element, or the solid scar tissue that has grown over the external surface of the implant [1].In our case, the Dacron knot may have been held against the scleral wall by the encircling band. The patient was highly myopic, another risk factor for intrusion. Moreover, the sclera was further weakened by the incision made for the drainage of the subretinal fluid. Cooper et al. reported a case in which a 5-0 Dacron scleral suture knot had eroded into the vitreous cavity 12 years after scleral laceration repair, pars plana vitrectomy, the removal of an intraocular foreign body, and a scleral buckling procedure for penetrating injury [6]. In their case, the Dacron suture was used to close the scleral laceration, and had been covered with a $5 \mathrm{~mm}$ radial scleral sponge and overlain with an encircling 240 band. In both Cooper's and our patients, the encircling band held the suture firmly against a sclera that had been compromised by a traumatic or surgical incision. Therefore, covering a nonabsorbable suture with an encircling band should be avoided in the buckling procedure, especially when the sclera is impaired by trauma, pathological myopia, or

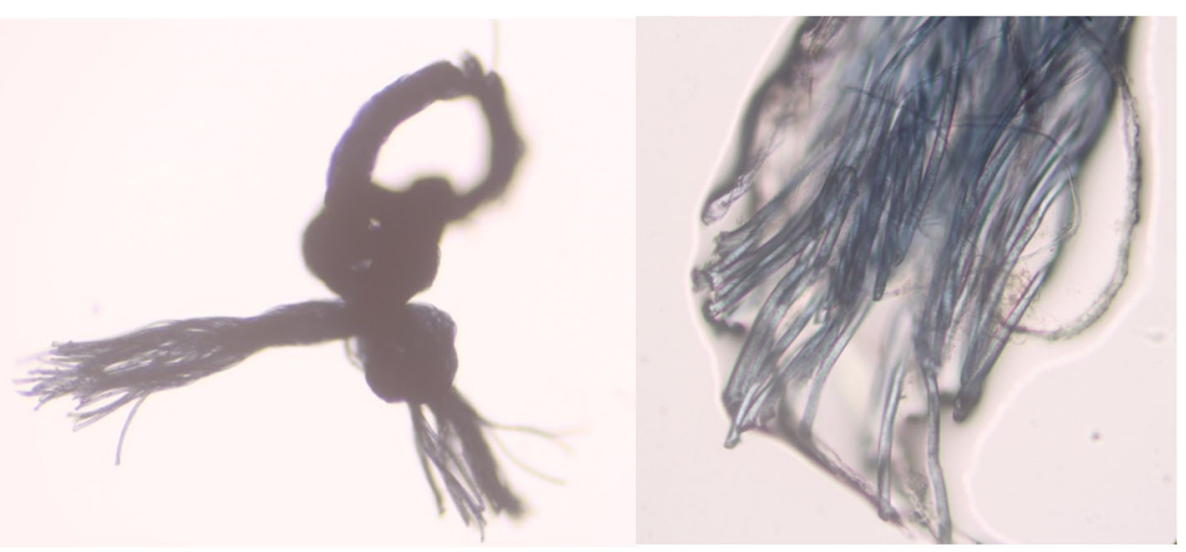

Fig. 4 Microscopic view of the suture node 


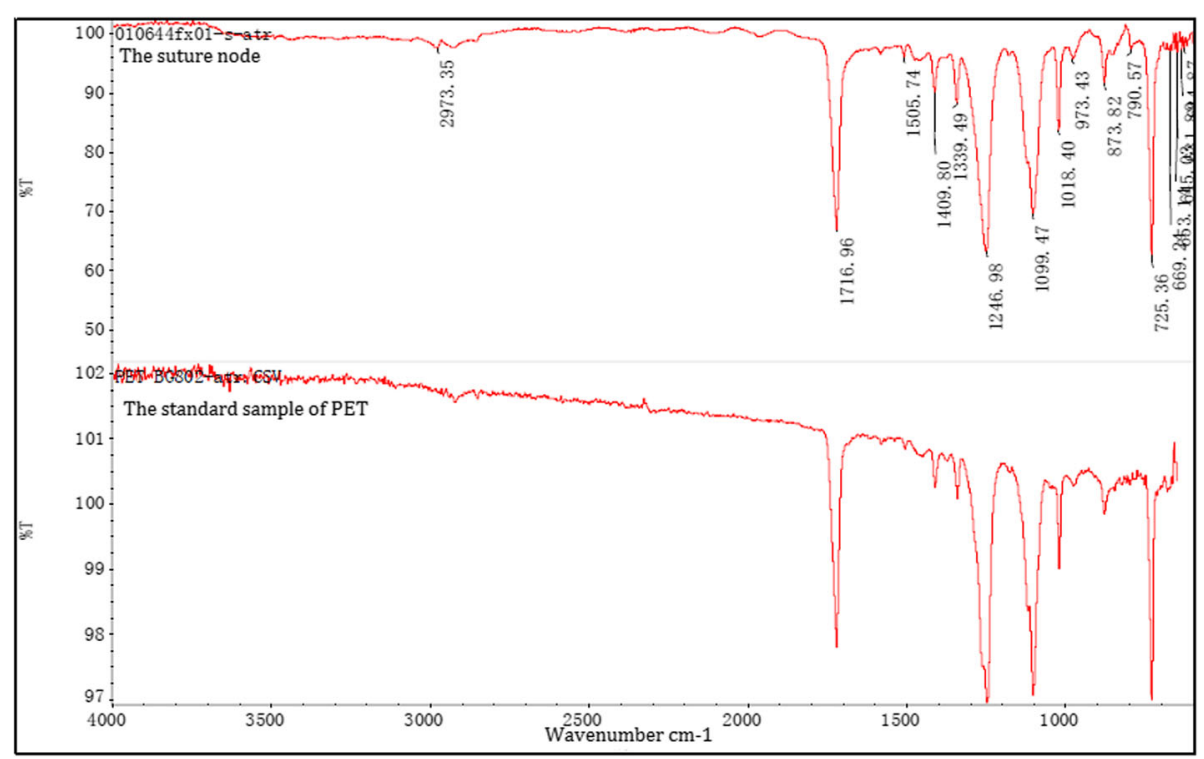

Fig. 5 Mass-spectrometric analysis revealed that the material was polyethylene terephthalate (PET)

surgical incision. If a suture is unavoidable, then a soft, absorbable suture may be preferable.

In conclusion, when covered with an encircling band, a nonabsorbable suture, which is usually placed where the sclera has already been compromised, could erode the sclera and intrude into the vitreous cavity.

\section{Abbreviations}

IOP: intra ocular pressure; PET: polyethylene terephthalate

\section{Acknowledgements}

Not applicable.

\section{Funding}

This work was supported by research grants from the National Natural Science Foundation of China (81570854) for designing the study and collecting data, the National Key Basic Research Program of China (2013CB967503) for analysis and interpretation data, and the Youth Project of the National Natural Science Fund 2018 (81800846) for writing the manuscript.

\section{Availability of data and materials}

All data generated and analyzed in this study are included within this manuscript.

\section{Authors' contributions}

RPG was a major contributor in acquisition of the data, literature search and manuscript draft. SF and GZX made contributions to conception and design, acquisition of data, and analysis and interpretation of data; XJC and GZX involved in drafting the manuscript and revising it critically for important intellectual content; $\mathrm{CHJ}$ did the surgery and participated in the revision of the manuscript. $\mathrm{HHZ}$ participated in the preparation and revision of the manuscript. All authors read and approved the final manuscript. All authors read and approved the final manuscript.

\section{Ethics approval and consent to participate}

Not applicable.

\section{Consent for publication}

Written informed consent was obtained from the patient for publication of this Case report. A copy of the written consent is available for review by the Editor of this journal.
Competing interests

The authors declare that they have no competing interests.

\section{Publisher's Note}

Springer Nature remains neutral with regard to jurisdictional claims in published maps and institutional affiliations.

\section{Author details}

${ }^{1}$ Department of Ophthalmology and Vision Science, Eye and ENT Hospital of Fudan University, 83 Fenyang Rd, Shanghai 200031, People's Republic of China. 2Department of Ophthalmology, Taizhou people's Hospital, Taizhou, Jiangsu, China. ${ }^{3}$ Department of Ophthalmology, People's Hospital of Shanghai, No. 5, Shanghai 200240, People's Republic of China. ${ }^{4}$ Shanghai Key Laboratory of Visual Impairment and Restoration, Fudan University, Shanghai 200031, China. ${ }^{5} \mathrm{NHC}$ Key Laboratory of Myopia (Fudan University), Laboratory of Myopia, Chinese Academy of Medical Sciences, Shanghai, China.

Received: 12 April 2018 Accepted: 29 November 2018

Published online: 17 December 2018

\section{References}

1. Nguyen QD, Lashkari K, Hirose T, Pruett RC, McMeel JW, Schepens CL. Erosion and intrusion of silicone rubber scleral buckle. Presentation and management Retina. 2001:21(3):214-20

2. Birgul T, Vidic B, El-Shabrawi Y. Intrusion of an encircling buckle after retinal detachment surgery. Am J Ophthalmol. 2003:136(5):942-4.

3. Yoshizumi MO, Friberg T. Erosion of implants in retinal detachment surgery. Ann Ophthalmol. 1983:15(5):430-4

4. Dogan M, Agca A, Turna F, Altan T, Eltutar K. Intraocular intrusion of suture material that was used as scleral buckling material. Retin Cases Brief Rep. 2014;8(3):227-9.

5. Sánchez-Vicente JL, Rueda-Rueda T, González-García ML, López-Herrero F, Sánchez-Vicente P. Retinal detachment caused by Arruga suture scleral intrusion. Treatment. Arch Soc Esp Oftalmol. 2015;90(10):494-6.

6. Cooper BA, Blinder KJ, Shah GK, Boniuk I. Intruding scleral sutures 12 years after primary repair. Arch Ophthalmol. 2004;122(8):1238-9.

7. Weinberger D, Lichter H, Gaton DD, Kremer I, Axer-Siegel R, Yassur Y. Intraocular intrusion of sutures after retinal detachment buckling surgery. Retina (Philadelphia, Pa). 1995:15(5):417-21.

8. REGAN CD. SCHEPENS CL: Erosion of the ocular wall by circling polyethylene tubing: a late complication of scleral buckling. Trans Am Acad Ophthalmol Otolaryngol. 1963;67:335-41. 
9. VAIL D. Erosion of the ocular wall by circling polyethylene tubing. A LATE COMPLICATION OF SCLERAL BUCKLING AM J OPHTHALMOL. 1964;57:83.

10. Greven CM, Kurup SK, Jacklin HN. Intraocular erosion and intrusion of an Arruga encircling suture. Retina. 2011;31(7):1437-8.

11. Kitagaki T, Morishita S, Kohmoto R, Fukumoto M, Suzuki H, Sato T, Kobayashi T, Kida T, Nakajima M, Ikeda T. A case of intraocular Erosion and intrusion by an Arruga suture. Case Rep Ophthalmol. 2016;7(1):174-8.

12. SCHEPENS CL, OKAMURA ID, BROCKHURST RJ. REGAN CD: scleral buckling procedures. V. Synthetic sutures and silicone implants. Arch Ophthalmol. 1960;64:868-81.

13. Postlethwait RW. Long-term comparative study of nonabsorbable sutures. Ann Surg. 1970;171(6):892-8.

Ready to submit your research? Choose BMC and benefit from:

- fast, convenient online submission

- thorough peer review by experienced researchers in your field

- rapid publication on acceptance

- support for research data, including large and complex data types

- gold Open Access which fosters wider collaboration and increased citations

- maximum visibility for your research: over $100 \mathrm{M}$ website views per year

At BMC, research is always in progress.

Learn more biomedcentral.com/submissions 